\title{
Correction to: Gaps and challenges: WHO treatment recommendations for tobacco cessation and management of substance use disorders in people with severe mental illness
}

\author{
Jayati Das-Munshi ${ }^{*}$, Maya Semrau ${ }^{2}$, Corrado Barbui ${ }^{3}$, Neerja Chowdhary ${ }^{4}$, Petra C. Gronholm ${ }^{5}$, Kavitha Kolappa ${ }^{6}$, \\ Dzmitry Krupchanka ${ }^{4}$, Tarun Dua ${ }^{4}$ and Graham Thornicroft ${ }^{5}$
}

\section{Correction to: BMC Psychiatry (2020) 20:237 https://doi.org/10.1186/s12888-020-02623-y}

Following publication of the original article [1], the authors identified an error in Table 1. The headings 'social exclusion', 'mental state impact' and 'physical health impact' were missing.

The original article has been corrected.

\section{Author details}

'Department of Psychological Medicine, Institute of Psychiatry Psychology \& Neurosciences, King's College London, South London \& Maudsley NHS-Trust, De Crespigny Park, London SE5 8AF, UK. ²Centre for Global Health Research, Brighton and Sussex Medical School, Brighton, UK. ${ }^{3}$ WHO Collaborating Centre for Research and Training in Mental Health and Service Evaluation, Department of Neuroscience, Biomedicine and Movement Sciences, Section of Psychiatry, University of Verona, Verona, Italy. ${ }^{4}$ Department of Mental Health and Substance Abuse, World Health Organization, Geneva, Switzerland. ${ }^{5}$ Centre for Global Mental Health, Institute of Psychiatry, Psychology \& Neuroscience, King's College London, London, UK. ${ }^{6}$ The Chester M. Pierce, MD Division of Global Psychiatry, Massachusetts General Hospital, Boston, USA
Published online: 23 June 2020

\section{Reference}

1. Das-Munshi J, et al. Gaps and challenges: WHO treatment recommendations for tobacco cessation and management of substance use disorders in people with severe mental illness. BMC Psychiatry. 2020;20: 237. https://doi.org/10.1186/s12888-020-02623-y.

The original article can be found online at https://doi.org/10.1186/s12888020-02623-y

* Correspondence: jayati.das-munshi@kcl.ac.uk

Jayati Das-Munshi and Maya Semrau are joint first authors and Tarun Dua and Graham Thornicroft are joint senior authors.

'Department of Psychological Medicine, Institute of Psychiatry Psychology \& Neurosciences, King's College London, South London \& Maudsley NHS-Trust, De Crespigny Park, London SE5 8AF, UK

Full list of author information is available at the end of the article

(c) The Author(s). 2020 Open Access This article is licensed under a Creative Commons Attribution 4.0 International License, which permits use, sharing, adaptation, distribution and reproduction in any medium or format, as long as you give appropriate credit to the original author(s) and the source, provide a link to the Creative Commons licence, and indicate if changes were made. The images or other third party material in this article are included in the article's Creative Commons licence, unless indicated otherwise in a credit line to the material. If material is not included in the article's Creative Commons licence and your intended use is not permitted by statutory regulation or exceeds the permitted use, you will need to obtain permission directly from the copyright holder. To view a copy of this licence, visit http://creativecommons.org/licenses/by/4.0/. The Creative Commons Public Domain Dedication waiver (http://creativecommons.org/publicdomain/zero/1.0/) applies to the data made available in this article, unless otherwise stated in a credit line to the data. 